J. clin. Path. (1947), 1, 39.

\title{
REPORT ON TWO SPECIES OF THE GENUS FUSIFORMIS OBTAINED FROM PATHOLOGICAL LESIONS IN MAN
}

\author{
BY \\ HERTA SCHWABACHER AND D. A. MITCHISON \\ E.M.S. Sector IV Central Laboratory, Watford, Herts
}

(RECEIVED FOR PUBlication, SEPTEMBER 21, 1945)

It is at present very difficult to classify accurately a given strain of the genus Fusiformis, and the following case histories may therefore be of interest.

\section{Clinical Histories}

Strain 1.-A woman aged 46 years was admitted to Shrodells Hospital, Watford, Hertfordshire, under the care of Dr. Duffus on Jan. 12, 1945, complaining of severe abdominal pain. Since Dec. 25, 1944, she had noticed frequency and pain on micturition. Her periods had been normal and bowels regular. Abdominal pain had become severe on Jan. 8. Her own doctor had administered $15 \mathrm{~g}$. sulphonamide; chemotherapy was discontinued in hospital.

On admission, her temperature was $98^{\circ} \mathrm{F}$.; pulse 112. There was extreme tenderness in the left inguinal region. Vaginal examination revealed fullness in the left fornix. The urine was normal. The blood showed leucocytosis and a "shift to the left" (red blood cells $5,090,000$ per 100 c.mm. of blood; $\mathrm{Hb} 70$ per cent ; colour index 0.7 ; white blood cells 17,200 ; polymorphs 75 per cent, band forms 15 per cent; eosinophils 2 per cent; basophils 1 per cent ; lymphocytes 18 per cent; large mononuclears 4 per cent.

A laparotomy was performed by Dr. Duffus on Jan. 12, 1945. One pocket of excessively foetid pus was found in the pouch of Douglas, and another pocket on the outer surface of the descending colon at the level of the iliac crest. The left Fallopian tube was dilated and inflamed. There was no diverticulitis or other abnormality of the abdominal viscera. A drainage tube was left in situ and the abdomen closed. There was free drainage of pus for several days. The patient made an uneventful recovery and was ready for discharge on Feb. 2, 1945.

Bacteriological examination of pus from the pelvic abscess.-Direct examination showed degenerate pus cells, numerous Gram-negative filamentous bacilli, and a few Gram-positive cocci in chains. The material was inoculated on to two horse-blood agar plates containing 6 per cent agar (Hayward and Miles,
1943), and on Nagler plates (Hayward, 1943), and into a tube of Robertson's cooked-meat medium. The Nagler plate failed to show the presence of $\mathrm{Cl}$.Welchii or $\mathrm{Cl}$. bifermentans. One blood-agar plate incubated aerobically remained sterile; the second-blood-agar plate, incubated anaerobically, when examined after seventy-two hours showed (1) numerous colonies, 0.2 to $0.5 \mathrm{~mm}$., opaque and slightly haemolytic, which were found to be composed of Gram-negative pleomorphic cells ; (2) seven-minute "dewdrop" colonies (in the pool), which finally conformed to Prevot's classification of Str. micros. The cooked-meat medium yielded Ps. pyocyanea in addition to these organisms.

Because of the resemblance of the anaerobic Gramnegative bacilli to those seen in profusion in direct smear, they were considered to be the cause of the abscess.

Strain 2.-A woman aged 62 years was admitted to Shrodells Hospital under the care of Dr. Roberts on July 4, 1945 ; she complained of a painless swelling in the region of the pubic symphysis which she had had for 3 or 4 days before admission. During this time she had also had diarrhoea. Her temperature was $102.6^{\circ} \mathrm{F}$. The lump in her pubic region was situated superficially, was 3 inches in its largest diameter, and was surrounded by a zone of erythema. She was placed on full dosage of sulphathiazole and her temperature rapidly fell to normal. On July 6 the abscess was opened and a large gangrenous slough removed. At the same time pus was taken for culture. The abscess healed well, and on Aug. 7 was only discharging slightly. On July 30 a radiograph of the pelvis failed to reveal any bony abnormality.

Bacteriological examination of the pus.-Direct examination showed pus cells, numerous Gramnegative bacilli, and a few Gram-positive cocci. The material was inoculated on to two horse-blood agar plates, containing 2 per cent agar, one of which was incubated aerobically and the other anaerobically. On the aerobic plate there was a scanty growth of three types of colony. One of these was a beta-haemolytic streptococcus which did not belong to Lancefield's 
groups A, B, C, or G. The other two were diphtheroids.

On the anaerobic plate, after forty-eight hours' incubation at $37^{\circ} \mathrm{C}$., there was a heavy growth of colonies about $0.6 \mathrm{~mm}$. in diameter, consisting of small Gramnegative bacilli. In view of its preponderance and the fact that the streptococcus did not belong to a Lancefield's group that is normally pathogenic in man, this anaerobic organism was probably the principal pathogen. As regards the remaining organisms isolated from the pus, the Gram-negative anaerobic bacillus was later found to demonstrate satellitism to one of the diphtheroids obtained from the aerobic plate.

\section{Description of the Two Strains of Gram-negative Anaerobic Bacilli}

Morphology.-The bacilli were grown on a Fildes slope and incubated in an atmosphere of 5 per cent $\mathrm{CO}_{2}$ and hydrogen for seventy-two hours.

Strain 1.-The cells varied considerably in length, being $0.5 \times 1.0-10.0 \mu$. They were Gramnegative bacilli and showed irregular staining, and globoid or oval bodies, $1.3 \mu$ in diameter, lying free or along the bacilli, swollen-ended bacilli, or filaments having a central distension. Many long filaments were curled upon themselves. Some were branched, but it was difficult to tell whether this was true or false branching. Cocco-bacillary forms

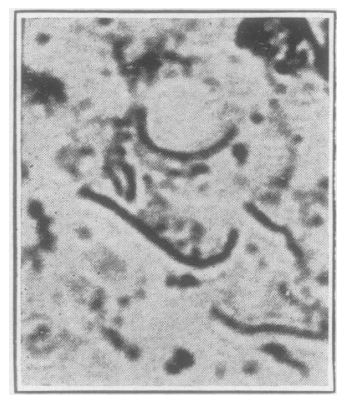

Strain 1, showing filamentous forms and globoid bodies when grown on enriched media. $(\times 1,000$.)

occurred in unenriched media. The organisms were non-motile, this being confirmed by flagella staining; non-capsulated; and did not contain spores (a culture did not survive heating for ten minutes at $80^{\circ} \mathrm{C}$.). The organism was not acidfast.

Strain 2.-The organism was a small Gramnegative bacillus, with parallel sides and rounded ends, about $0.2 \times 0.6-2.5 \mu$. It stained uniformly with carbol fuchsin, showing little pleomorphism and no branching. No capsules or spores were demonstrated, and it was not acid-fast. In Fildes broth incubated under the same conditions there was rather more pleomorphism with coccal and long filamentous forms up to $10 \mu$ in length. Large globoid bodies or distensions in the filaments. were never seen. The organisms were non-motile, as confirmed by flagella staining.

Colonial morphology.-Colonies were grown on blood-agar plates containing 2 per cent agar and incubated at $37^{\circ} \mathrm{C}$. for seventy-two hours in a microaerophilic atmosphere (i.e., the pressure in a jar was lowered to $260 \mathrm{~mm}$. $\mathrm{Hg}$ and the vacuum replaced with hydrogen.

Strain 1.-The colony was between 1 and $1.5 \mathrm{~mm}$. in diameter, grey, circular, with an entire edge, semi-translucent, slightly haemolytic, but never frankly beta-haemolytic, raised, convex, smooth, shiny, compact, of a butyrous consistency, and easily emulsifiable.

Strain 2.-This was similar to strain 1, but no haemolysis was present.

\section{Growth requirements}

Strain 1.-After recent isolation, the strain failed to grow in peptone water, broth, or gelatine agar. The addition of Fildes extract in a concentration of 1 per cent yielded prolific growth. Peptone water with $\mathrm{V}$ factor, with $\mathrm{X}$ factor, and with $\mathbf{V}$ and $\mathbf{X}$ factors yielded growth. Satellitism to a Staph. albus colony on an agar plate was marked after seventy-two hours' incubation. About six months after isolation the organism was found to be capable of growing in peptone water and broth.

Cultures incubated in 5 per cent carbon dioxide in hydrogen, under microaerophilic conditions and under anaerobic conditions yielded colonies whose mean diameters were $0.60 \mathrm{~mm}$., $0.44 \mathrm{~mm}$., and $0.08 \mathrm{~mm}$. respectively. No growth was obtained in 5 per cent carbon dioxide in air, or aerobically. Fildes-agar shake cultures showed a heavy band of growth $12 \mathrm{~mm}$. below the surface of the agar. Smaller colonies grew right to the bottom of the tube, but no colonies developed above the band. For up to five days the colonies were translucent, lenticular, and gave the appearance of gas bubbles ; later they became opaque and the agar was split by gas.

Strain 2.-This was similar to strain 1, except that poor growth was obtained in peptone water soon after isolation. Addition of Fildes extract or $\mathrm{V}$ and $\mathrm{X}$ factors increased the amount of growth. In the Fildes-agar shake culture, growth was maxi- 
TABLE I

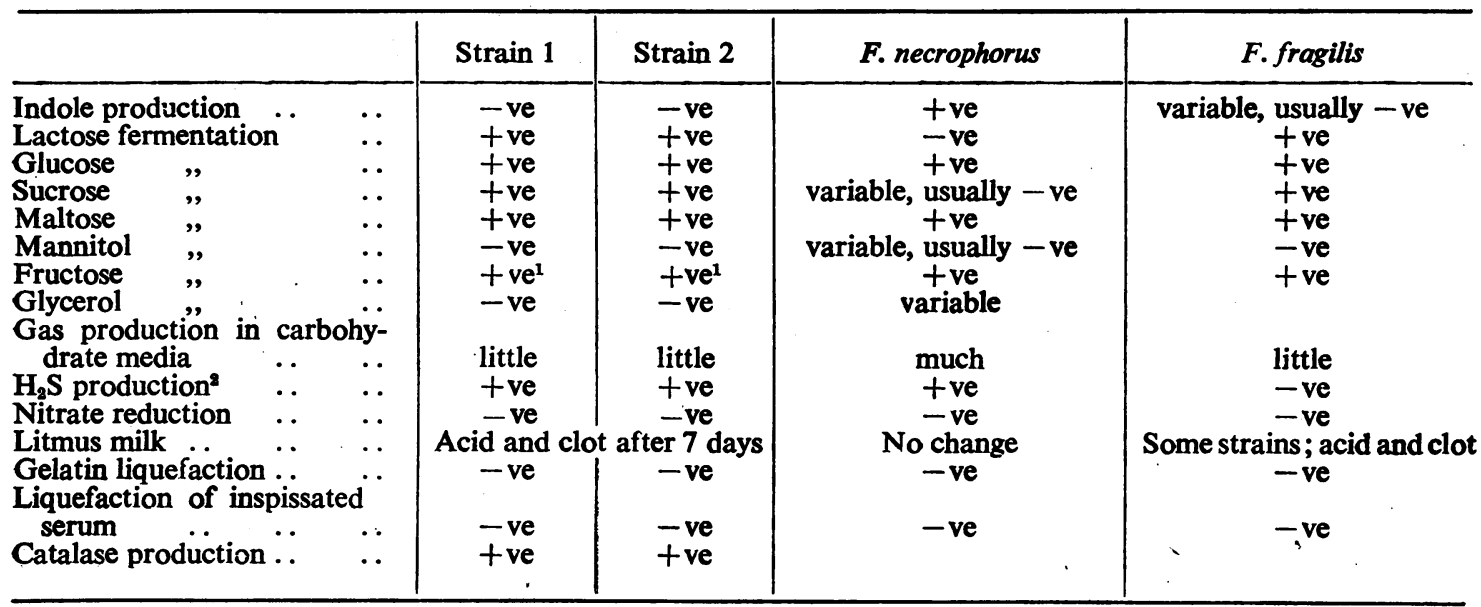

1 Acid but no gas in fructose.

2 Growth on a Fildes slope tested by blackening of a lead acetate paper; +ve $35 \mathrm{~mm}$. in 24 hours.

TABLE II

\begin{tabular}{|c|c|c|c|c|c|c|c|c|c|c|}
\hline \multirow{2}{*}{ Date } & \multirow{2}{*}{ Animal } & \multirow{2}{*}{$\begin{array}{l}\text { Mode of } \\
\text { inoculation }\end{array}$} & \multirow{2}{*}{ Killed } & \multicolumn{2}{|c|}{ Enlarged glands } & \multicolumn{4}{|c|}{$\begin{array}{l}\text { Organism recovered on } \\
\text { culture from }\end{array}$} & \multirow{2}{*}{ Titre } \\
\hline & & & & Inguinal & Sublumbar & $\begin{array}{l}\text { Local } \\
\text { lesion }\end{array}$ & Gland & $\begin{array}{l}\text { Heart } \\
\text { blood }\end{array}$ & Spleen & \\
\hline $\begin{array}{l}* 7.7 .45 \\
20.3 .45\end{array}$ & Mouse & $\begin{array}{l}\text { Intramuscular aa } 5 \% \\
\mathrm{CaCl}_{2} \text { and cooked- } \\
\text { meat culture }\end{array}$ & $\begin{array}{r}9.7 .45 \\
26.3 .45\end{array}$ & + & + & + & $\bar{t}$ & $\overline{-}$ & $\overline{-}$ & \\
\hline 20.3.45 & Mouse & $\begin{array}{l}\text { Intramuscular } 0.5 \mathrm{ml} \text {. } \\
\text { cooked-meat culture }\end{array}$ & 26.3.45 & + & + & - & - & - & - & \\
\hline $\begin{array}{l}* 31.7 .45 \\
20.3 .45\end{array}$ & Mouse & $\begin{array}{l}\text { Intraperitoneal } 0.2 \mathrm{ml} \text {. } \\
\text { cooked-meat culture }\end{array}$ & $\begin{array}{l}10.8 .45 \\
26.3 .45\end{array}$ & $\overline{-}$ & + & - & $\overline{-}$ & $\overline{-}$ & $\overline{-}$ & \\
\hline 26.3.45 & Mouse & $\begin{array}{l}\text { Intramuscular aa } 5 \% \\
\mathrm{CaCl}_{2} \text { and cooked- } \\
\mathrm{m} \text { at culture }\end{array}$ & 14.4 .45 & + & + & + & + & - & - & \\
\hline 20.3 .45 & $\begin{array}{l}\text { Guinea- } \\
\text { pig }\end{array}$ & $\begin{array}{l}\text { Intramuscular } 1.0 \mathrm{ml} \text {. } \\
\text { cooked-meat culture }\end{array}$ & 14.4 .45 & - & - & - & - & - & - & 20 \\
\hline 26.3.45 & Rabbit & $\begin{array}{l}\text { Intralabially. } \\
\text { Left lip, } 0.2 \text { ml. } \mathrm{CaCl}_{2} \\
+0.2 \mathrm{ml} \text { saline } \\
\text { Right lip, } 0.2 \mathrm{ml} \text {. } \\
\mathrm{CaCl}_{2}+0.2 \mathrm{ml} . \text { cul- } \\
\text { ture }\end{array}$ & 30.5 .45 & - & - & - & - & - & - & $<2$ \\
\hline \multirow[t]{2}{*}{26.3 .45} & Rabbit & $\begin{array}{c}\text { Intravenous } 1.0 \mathrm{ml} \text {. } \\
\text { cooked-meat culture }\end{array}$ & 30.5 .45 & - & - & - & - & - & - & 16 \\
\hline & $\begin{array}{l}10 \text { normal } \\
\text { human } \\
\text { sera }\end{array}$ & . & & & & & & $\therefore$ & & $<20$ \\
\hline
\end{tabular}


mal at $7 \mathrm{~mm}$. below the surface, but no gas was produced. Colony size was increased in an atmosphere containing carbon dioxide as much as with strain 1.

In Fildes broth both strains produced an even turbidity with a slight ropy deposit after fortyeight hours.

Strain 1 survived three weeks in cooked-meat medium.

Heat resistance.-Both strains failed to survive five minutes at $60^{\circ} \mathrm{C}$.

Biochemical activities.-These were tested with strips of iron in sugar tubes and the results are listed in Table $I$.

Drug sensitivity.-Both strains were sensitive to $5 \mathrm{mg}$. per cent sulphadiazine, sulphamezathine, sulphapyridine, sulphathiazole, and sulphanilamide (Harper and Cawston, 1945). The minimal bactericidal concentration of penicillin for strain 1 was 62 units per ml., while for strain 2 it was between 10 and 20 units per $\mathrm{ml}$.

Biological tests.-From the biological tests of strain 1, listed in Table II, it will be seen that the strain proved completely non-pathogenic to the laboratory animals used. Mice receiving intramuscular inoculations of $0.25 \mathrm{ml}$. of 5 per cent calcium chloride with $0.25 \mathrm{ml}$. cooked-meat culture showed enlargement of their proximal glands. From these glands the fusiform organism was recovered on culture. Because of the morphological resemblance of this bacillus to $F$. necrophorus, a rabbit received intralabial inoculation. No necrosis developed during a two months' period of observation.

Serological examination of rabbits and a guineapig failed to reveal any agglutinin response to the organism inoculated; similarly ten sera, sent to the laboratory for Wassermann test, failed to agglutinate a suspension of the test strain in a final dilution of 1 in 20 .

In the case of strain 2, only mice were tested. They received intramuscular injection of the culture with calcium chloride and intraperitoneal injection with cooked-meat culture.

\section{Discussion}

Organisms of the genus Fusiformis are the predominant flora of the gastro-intestinal tract, and from faeces a very large variety of strains can be obtained with widely variable characteristics (Eggerth and Gagnon, 1933). Other members of the group cause suppurative lesions of mucous membrane and abscesses in tissues close to the gut, the vagina, and the genito-urinary system. They have been studied for many years from the bacteriological and clinical standpoint by French workers (Lemierre, 1936, who gives the main French references) and more recently in America (Dack, 1940, who gives a fairly full bibliography). In all probability infections with these organisms are more common than is realized in this country.

Of the various described species the following two have been studied most completely and are most closely related to the strains we have isolated. However, lack of uniformity in technique, inadequate description of individual strains, and conclusions based on the study of only a few strains make comparisons of different workers' results difficult. The first species, name Fusiformis necrophorus (Topley and Wilson, 1936), Schmorl's bacillus (Weinberg and others, 1937), Bacteroides necrophorus, etc., is probably identical with Bacillus funduliformis (Weinberg and others; Dack and others, 1938). Fairly full descriptions have been given by Henthorne and others, 1936; Tessier and others, 1931 ; and by Dack and others, 1938. All authors agree that, morphologically, this is a non-motile, Gram-negative bacillus, usually ovoid, with biopular staining in exudates, and, in culture, highly pleomorphic, with long filamentous forms, often swollen. There are often large globoid bodies, irregular staining of the filamentous forms, and frequently false branching. The significance of the large spheroidal bodies found in cultures of "Bacteroides funduliformis" is discussed by Dienes and Smith (1944). They interpret them as a sign of a reproductive process different from binary fission. However, throughout a series of papers on the subject they do not appear to have investigated their strains apart from the morphology and growth requirements. In the full descriptions by the other authors quoted there is agreement that colonies are constantly haemolytic. Tessier and others describe haemolysis in blood glucose agar shake cultures resembling that of a beta-haemolytic streptococcus, while Dack and others state that on first removing a bloodagar plate from an anaerobic jar there is no haemolysis. As soon, however, as the blood becomes oxidized there is a wide area of green discoloration round the colonies, which usually changes to clear haemolysis on standing.

It appears that in liquid media there is a growth at the bottom of the tube and a clear supernatant fluid. 
As regards biochemical activities, Table I illustrates the results obtained by these authors. No strains investigated fermented lactose. Some strains appear to be able to produce gas and a little acid in carbohydrate-free basic media, which may account for some of the discrepancies. All strains produce gas as well as acid with fermentable carbohydrates.

The organism is often pathogenic to rabbits, causing, on subcutaneous injection, an abscess which may spread and finally kill the animal with metastatic abscesses in the lungs. Intravenous injections may cause abscesses in the lungs, liver, and joints. Reports differ as to the pathogenicity of all strains. Those obtained from liver abscesses in cattle are more pathogenic than those from lesions in man. The mouse is less susceptible than the rabbit, while the guinea-pig is immune.

The second species is called Fusiformis fragilis (Topley and Wilson, 1936). It has been described by Henthorne and others (1936), and by Cohen (1932). In contradistinction to the first group, the organism is not pleomorphic and resembles a coliform bacillus in its morphology. The large spheroidal forms characteristic of necrophorus are not found. The colonies are usually smaller than those of necrophorus and are not haemolytic. In broth there is uniform turbidity. The biochemical reactions are given in Table I. In rabbits subcutaneous injection causes a local abscess, but in general the organism is less pathogenic than necrophorus.

The main distinction between necrophorus and fragilis is usually based on morphology, haemolysis, and the production of indole and hydrogen sulphide, but it appears to us that the fermentation of lactose is also important. However, in view of the fact that the pleomorphism of necrophorus is often present on certain media only, we feel that morphology is an uncertain criterion for differentiation.

As regards the two organisms described by us, No. 1 is similar to fragilis in all points except that of hydrogen sulphide production and of its morphology, which is typical of necrophorus. Methods of testing hydrogen sulphide production used in the reported descriptions of fragilis and necrophorus vary considerably in sensitivity, so that we doubt the significance of this difference. Furthermore, this organism would have had a morphology typical of fragilis had it been investigated in unenriched media alone, so that we are led to doubt the significance of a distinction between necrophorus and fragilis based on morphology alone. The haemolysis described for necrophorus is far more intense and of a character different from that observed in strain 1.

Strain 2 fits with the description of fragilis given above, again with the exception of hydrogen sulphide production.

Of the remaining members of the genus Fusiformis, F. fusiformis (Topley and Wilson, 1936) is separated off on the basis of having pointed ends, and $F$. serpens on motility and liquefaction of gelatin. There are other strains incompletely described.

In conclusion we must emphasize that the full importance of infections caused by these organisms will not be recognized until methods of anaerobic culture are used on a much wider scale than before. Few people realize that anaerobic technique is little more difficult than careful work with aerobic bacteria.

\section{Summary}

Two bacterial strains isolated from pathological lesions in man and belonging to the fusiform genus have been described, and their position in regard to the classification of this group has been discussed. They are most closely allied to the species F. fragilis.

\section{REFERENCES}

Cohen, J. (1932). Arch. Surg., 24, 171.

Dack, G. M. (1940). Bact. Rev., 4, 227.

Dack, G. M., Dragstedt, L. R., Johnson, R., and McCullough, N.B. (1938). J. infect. Dis., 62, 169.

Dienes, L., and Smith, W. E. (1944). J. Bact., 48, 125

Eggerth, A. H., and Gagnon, B. H. (1933). J. Bact., 25, 389.

Harper, G. J., and Cawston, W. C. (1945). J. Path. Bact., 57, 59.

Hayward, N. J. (1943). J. Path. Bact., 55, 285.

Hayward, N. J., and Miles, A. A. (1943). Lancet, 2, 116.

Henthorne, J. C., Thompson, L., and Beaver, D. C. (1936). J. Bact., $31,255$.

Lemierre, A. (1936). Lancet, 1, 701.

Teissier, P., Reilly, J., Rivalier, E., and Stéfanesco, V. (1931). Ann.

Méd., 30,97 . teriology and Immunity." London.

Weinberg, M., Nativelle, R., and Prévot, A. R. (1937). “Les Microbes Anaérobies." Paris. Masson et Cie. 